\title{
Novel Algicides against Bloom-Forming Cyanobacteria from Allelochemicals: Design, Synthesis, Bioassay, and 3D-QSAR Study
}

\author{
Yin Luo ${ }^{1,2}$, Yushun Yang ${ }^{3}$, Wenguang Hou ${ }^{1, *}$ and Jie $\mathrm{Fu}^{2, *}$ (1) \\ 1 Department of Biomedical Engineering, School of Life Science and Technology, Huazhong University of \\ Science and Technology, Wuhan 430074, China; 2019511006@hust.edu.cn \\ 2 School of Environmental Science and Engineering, Huazhong University of Science and Technology, \\ Wuhan 430074, China \\ 3 State Key Laboratory of Pharmaceutical Biotechnology, School of Life Sciences, Nanjing University, \\ Nanjing 210093, China; ys_yang@nju.edu.cn \\ * Correspondence: houwg@hust.edu.cn (W.H.); jiefu@hust.edu.cn (J.F.); Tel.: +86-27-8779-2101 (J.F.)
}

check for updates

Citation: Luo, Y.; Yang, Y.; Hou, W.; Fu, J. Novel Algicides against Bloom-Forming Cyanobacteria from Allelochemicals: Design, Synthesis, Bioassay, and 3D-QSAR Study. Biology 2021, 10, 1145. https:// doi.org/10.3390/biology10111145

Academic Editor: Ian Blaby

Received: 29 September 2021 Accepted: 4 November 2021 Published: 6 November 2021

Publisher's Note: MDPI stays neutral with regard to jurisdictional claims in published maps and institutional affiliations.

Copyright: (c) 2021 by the authors. Licensee MDPI, Basel, Switzerland. This article is an open access article distributed under the terms and conditions of the Creative Commons Attribution (CC BY) license (https:// creativecommons.org/licenses/by/ $4.0 /)$.
Simple Summary: Due to the frequent outbreaks of cyanobacteria bloom worldwide, research on novel algicides has attracted more and more attention. At present, allelochemicals have been reported as promising natural algicides. However, current studies mainly focus on the parent compounds, and the structural modification of original allelochemicals has been rarely involved. In this study, phenolic acid derivatives were innovatively synthesized as potential algicides, and lead compounds with excellent activity were found. For instance, upon the algicidal activity on Aphanizomenon flos-aquae, the $\mathrm{EC}_{50}$ of the best active compound 18 reached $0.63 \mu \mathrm{M}(0.17 \mathrm{mg} / \mathrm{L})$, while the $\mathrm{EC}_{50}$ values of previously reported allelochemicals have been basically at the $\mathrm{mg} / \mathrm{L}$ level. The result indicates that the algicides reported in this study are more efficient at inhibiting cyanobacteria with lower effective concentrations than most previously reported compounds. Moreover, 3D-QSAR models were constructed and provided a theoretical guidance for further structure optimization of compounds to achieve better algicidal activity.

Abstract: Cyanobacteria bloom caused by water eutrophication has threatened human health and become a global environmental problem. To develop green algicides with strong specificity and high efficiency, three series of ester and amide derivatives from parent allelochemicals of caffeic acid (CA), cinnamic acid (CIA), and 3-hydroxyl-2-naphthoic acid (HNA) were designed and synthesized. Their inhibitory effects on the growth of five harmful cyanobacterial species, Microcystis aeruginosa ( $M$. aeruginosa), Microcystis wesenbergii (M. wesenbergii), Microcystis flos-aquae (M. flos-aquae), Aphanizomenon flos-aquae (Ap. flos-aquae), and Anabaena flos-aquae (An. flos-aquae), were evaluated. The results revealed that CIA esters synthesized by cinnamic acid and fatty alcohols showed the best inhibition effect, with $\mathrm{EC}_{50}$ values ranging from 0.63 to $>100 \mu \mathrm{M}$. Moreover, some CIA esters exhibited a good selectivity in inhibiting cyanobacteria. For example, the inhibitory activity of naphthalen-2-yl cinnamate was much stronger on Ap. flos-aquae $\left(\mathrm{EC}_{50}=0.63 \mu \mathrm{M}\right)$ than other species $\left(\mathrm{EC}_{50}>10 \mu \mathrm{M}\right)$. Threedimensional quantitative structure-activity relationship (3D-QSAR) analysis was performed and the results showed that the steric hindrance of the compounds influenced the algicidal activity. Further mechanism study found that the inhibition of CIA esters on the growth of M. aeruginosa might be related to the accumulation of malondialdehyde (MDA).

Keywords: cyanobacteria; allelochemicals; algicide; phenolic acid; 3D-QSAR

\section{Introduction}

With the increase of human activities, water eutrophication has become a prominent and global problem [1]. Eutrophic water is rich in nitrogen, phosphorus, and other nutrients, 
which leads to the excessive propagation of harmful blue-green algae (cyanobacteria) and the formation of cyanobacteria bloom [2,3]. With the impact of cyanobacteria bloom, the dissolved oxygen content in the water decreases, a large number of fish and other organisms die, and the whole ecosystem is seriously damaged. Cyanobacteria can also produce a variety of toxins (such as microcystin, nodularin, and cylindropermopsin), which may threaten human health [4]. How to inhibit the growth of cyanobacteria has become a hot topic in the field of environmental protection and the common measure is to apply chemical algicides. However, the application of algicides has some limitations, including easily causing secondary pollution and lack of enough inhibition specificity on target algae [5]. Therefore, the development of green algicides with strong specificity and high efficiency is urgently needed.

Allelochemicals refer to the chemical substances released from plants or microorganisms that affect the growth of adjacent plants or microorganisms $[6,7]$. Previous studies showed that organic acids and their derivatives extracted from plants have strong inhibitory effects on algal growth [8]. Caffeic acid (CA), cinnamic acid (CIA), and naphthoic acid (NA), as common allelochemicals extracted from plants, have been reported to inhibit the growth of some algae [8-10]. He et al. [11] found that CIA had an inhibitory effect on Microcystis aeruginosa (M. aeruginosa), a dominant species in cyanobacteria bloom, with an $\mathrm{EC}_{50}$ of $0.487 \mathrm{mmol} / \mathrm{L}$. Gao et al. [12] extracted four phenolic acids, including CA, from Hydrilla verticillata and Vallisneria spiralis, and found that the four substances had synergetic inhibition on M. aeruginosa. These positive results encourage us to find more efficient green algicides from the derivatives of organic acids.

In addition, the species diversity of cyanobacteria increases the difficulty of controlling cyanobacteria bloom by using algicides. For example, there are 12 species from Microcystis and 13 species from Anabaena contributing to the cyanobacteria bloom in Taihu Lake, China [13]. The dominant species of cyanobacteria in Taihu Lake are Microcystis spp., while the dominant species in Wuli Lake, an inner lake of Taihu Lake, are filamentous cyanobacteria. When cyanobacteria bloom breaks out, dominant species may change with the seasonal succession [14]. The succession rule of the cyanobacteria in Taihu Lake was found as: Microcystis flos-aquae (M. flos-aquae) was dominant in spring, Microcystis wesenbergii ( $M$. wesenbergii) in summer, $M$. wesenbergii and M. aeruginosa in autumn, and M. flos-aquae and Microcystis panniformis in winter [13]. Therefore, it is necessary to apply efficient and specific algicides for the control of cyanobacteria bloom with consideration of the dominant species as well as the variation in different seasons.

In this study, three series of ester and amide derivatives were designed and synthesized from the parent compounds: CIA, CA, and 3-hydroxy-2-naphthoic acid (HNA). Their inhibitory effects on the growth of five harmful cyanobacteria species with toxin production capacity [15-18], M. aeruginosa, M. wesenbergii, M. flos-aquae, Aphanizomenon flos-aquae (Ap. flos-aquae), and Anabaena flos-aquae (An. flos-aquae), were evaluated. The structure-activity relationship was discussed, and three-dimensional quantitative structure-activity relationship (3D-QSAR) analysis was performed. Moreover, physiological assays for examination of the total soluble protein content, superoxide dismutase (SOD) activity, and malondialdehyde (MDA) content were performed to explore possible action mechanisms. The purpose of this study was to find efficient and specific lead compounds of green algicides for the control of cyanobacteria bloom.

\section{Materials and Methods}

\subsection{Chemistry General}

All used chemicals of reagent grade were purchased from Aldrich (USA). Separation of the compounds by column chromatography was carried out with silica gel 60 (200-300 mesh ASTM, E. Merck, Darmstadt, Germany). The quantity of silica gel used was 50-100 times the weight charged on the column. Thin-layer chromatography (TLC) was run on the silica gel-coated aluminum sheets (silica gel 60 GF254, E. Merck, Darmstadt, Germany) and visualized under UV light ( $254 \mathrm{~nm}$ ). Melting points (uncorrected) were obtained by using 
an XT4 MP apparatus (Taike Corp. Beijing, China). ${ }^{1} \mathrm{H}$ NMR spectra were recorded at $300 \mathrm{MHz}$ on ${ }^{1} \mathrm{H}$-Varian-Mercury- 300 spectrometers at $25^{\circ} \mathrm{C}$, using tetramethylsilane (TMS) as internal standard. ESI MS were recorded with a Mariner System 5304 mass spectrometer. Elementary analyses were performed on a CHN-O-Rapid instrument.

\subsection{Synthesis of Caffeic Acid Esters}

Caffeic acid (2.5 mmol) was dissolved in $5 \mathrm{~mL}$ of $\mathrm{N}, \mathrm{N}$-dimethylformamide (DMF). Alcohol or phenol ( $2.5 \mathrm{mmol})$ was added, following by $10 \mathrm{~mL}$ of $\mathrm{CH}_{2} \mathrm{Cl}_{2}$ solution of 1-ethyl3-(3-dimethylaminopropyl) carbodiimide hydrochloride (EDC $\cdot \mathrm{HCl}, 3 \mathrm{mmol}$ ). The mixture was stirred at room temperature for $6-10 \mathrm{~h} . \mathrm{CH}_{2} \mathrm{Cl}_{2}$ was removed under reduced pressure and the solution was diluted using $40 \mathrm{~mL}$ of water. The products were extracted using ethyl acetate (EtOAc). The extract was dried using $\mathrm{MgSO}_{4}$, filtered, and evaporated. The residue was purified on a silica gel column (EtOAc-petroleum ether (peth)) to give CA esters (1-5). The synthesis route of compounds $\mathbf{1 - 5}$ is shown in Scheme 1 . The characterization data for compounds 1-5 are given in the Supplementary Materials S1.

\subsection{Synthesis of Caffeic Acid Amides}

Caffeic acid ( $5 \mathrm{mmol}$ ) was dissolved in $10 \mathrm{~mL}$ of DMF, and $0.7 \mathrm{~mL}$ of triethanolamine (TEA) (5 mmol) were added. The solution was cooled in an ice-water bath, and amine (5 mmol) was added, following by $10 \mathrm{~mL}$ of $\mathrm{CH}_{2} \mathrm{Cl}_{2}$ solution of butyloctyl phthalate (BOP, $5 \mathrm{mmol})$. The mixture was stirred at $0{ }^{\circ} \mathrm{C}$ for $30 \mathrm{~min}$ and then at room temperature for $2-5 \mathrm{~h}$. $\mathrm{CH}_{2} \mathrm{Cl}_{2}$ was removed under reduced pressure and the solution was diluted with $80 \mathrm{~mL}$ of water. The products were extracted with EtOAc. The extract was washed successively with $1 \mathrm{~N} \mathrm{HCl}$, water, $1 \mathrm{M} \mathrm{NaHCO}_{3}$, and water, dried using $\mathrm{MgSO}_{4}$, filtered and evaporated. The residue was purified on a silica gel column (EtOAc-peth) to give CA amides (6-12). The synthesis route of compounds 6-12 is shown in Scheme 1. The characterization data for compounds 6-12 are given in the Supplementary Materials S1.

\subsection{Synthesis of Cinnamic Acid Esters}

Cinnamic acid ( $2.5 \mathrm{mmol}$ ) was dissolved in $10 \mathrm{~mL}$ of $\mathrm{CH}_{2} \mathrm{Cl}_{2}$. Alcohol or phenol ( $2.5 \mathrm{mmol}$ ) was added, following by $10 \mathrm{~mL}$ of $\mathrm{CH}_{2} \mathrm{Cl}_{2}$ solution of $\mathrm{EDC} \cdot \mathrm{HCl}(3 \mathrm{mmol})$. The mixture was stirred at room temperature for $6-10 \mathrm{~h}$. Then, the solution was dried using $\mathrm{MgSO}_{4}$, filtered, and evaporated. The residue was purified on a silica gel column (EtOAcpeth) to give CIA esters (13-24). The synthesis route of compounds 13-24 is shown in Scheme 1 . The characterization data for compounds 13-24 are given in the Supplementary Materials S1.

\subsection{Synthesis of 2-Hydroxy-3-Naphthoic Acid Esters}

The method was the same as that of the synthesis of CIA esters (26-31). 25 was the main by-product during the reaction via lactonization of 2-hydroxy-3-naphthoic acid. The synthesis route of compounds $\mathbf{2 6 - 3 1}$ is shown in Scheme 1. The characterization data for compounds 25-31 are given in the Supplementary Materials S1.

\subsection{Algicidal Activity Assay}

M. aeruginosa, M. wesenbergii, M. flos-aquae, Ap. flos-aquae, and An. flos-aquae were provided by the Freshwater Algae Culture Collection of the Institute of Hydrobiology, Chinese Academy of Sciences (Wuhan, China). The culture conditions were as follows: BG11 medium ( $25 \mathrm{~mL}$, Erlenmeyer flasks), 12-h light/12-h dark cycle, and $25^{\circ} \mathrm{C}$. The flasks were shaken 3 times/day, making cyanobacterial cells grow into the logarithmic phase. For the algicidal activity assay, different doses $(0,1,10$, and $100 \mu \mathrm{mol} / \mathrm{L})$ of compounds were added into $25 \mathrm{~mL}$ of sterilized BG11 culture medium, and the solution was mixed uniformly by hand. Then, the cyanobacterium was inoculated into the culture medium with an initial density of $10^{6}$ cell/L, and cultured for $96 \mathrm{~h}$ with shaking twice in the daytime. Then, $0.5 \mathrm{~mL}$ of uniform cyanobacteria solution were withdrawn and the algal density was 
counted. $\mathrm{EC}_{50}$ was calculated based on the dose-response experiments by the probit unit method using the software SPSS.<smiles>[R20]NC(=O)/C=C/c1ccc(O)c(O)c1</smiles>

$6-12$

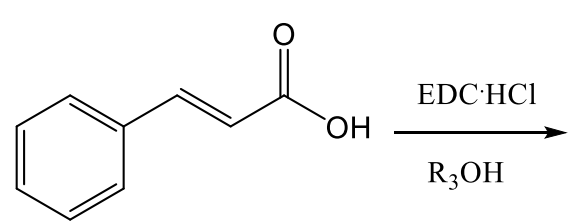<smiles>O=C(O)c1cc2ccccc2cc1O</smiles><smiles>[R6]OC(C)C1CC1</smiles>
$\mathrm{EDC} \cdot \mathrm{HCl}$<smiles>O=C1Oc2cc3ccccc3cc21</smiles>

25<smiles>[R1]OC(=O)/C=C/c1ccc(O)c(O)c1</smiles>

$$
\begin{array}{ll}
1: \mathrm{R}_{1}=4-\mathrm{NO}_{2}-\mathrm{Ph}- & 6: \mathrm{R}_{2}=\left((i-\mathrm{Pr})_{2^{-}}\right. \\
2: \mathrm{R}_{1}=2,4,6-\left(\mathrm{NO}_{2}\right)_{3}-\mathrm{Ph}- & 7: \mathrm{R}_{2}=\mathrm{Benzyl}- \\
3: \mathrm{R}_{1}=\mathrm{Ph}-\mathrm{Et}- & 8: \mathrm{R}_{2}=(n-\mathrm{Pr})_{2}{ }^{-} \\
4: \mathrm{R}_{1}=\text { Et- } & 9: \mathrm{R}_{2}=\mathrm{Et}- \\
5: \mathrm{R}_{1}=\mathrm{Ch}- & 10: \mathrm{R}_{2}=\mathrm{H}^{-} \mathrm{H}_{2} \mathrm{O} \\
& 11: \mathrm{R}_{2}=4-\mathrm{Me}-\mathrm{Ph}- \\
& 12: \mathrm{R}_{2}=(n-\mathrm{Bu})_{2^{-}}
\end{array}
$$<smiles>[R3]OC(=O)/C=C/c1ccccc1</smiles>

$13-24$

$$
\begin{array}{ll}
13: \mathrm{R}_{3}=4-\mathrm{NO}_{2}-\mathrm{Ph}- & 14: \mathrm{R}_{3}=2,4,6-\left(\mathrm{NO}_{2}\right)_{3}-\mathrm{Ph}- \\
15: \mathrm{R}_{3}=t-\mathrm{Bu}- & 16: \mathrm{R}_{3}=\mathrm{Cy}- \\
17: \mathrm{R}_{3}=\mathrm{Et}- & 18: \mathrm{R}_{3}=\mathrm{Naphth}- \\
19: \mathrm{R}_{3}=i-\mathrm{Pr}- & 20: \mathrm{R}_{3}=n-\mathrm{Bu}- \\
21: \mathrm{R}_{3}=i-\mathrm{Bu}- & 22: \mathrm{R}_{3}=\mathrm{Ph}-\mathrm{Me}- \\
23: \mathrm{R}_{3}=\mathrm{Me}- & 24: \mathrm{R}_{3}=n-\text { Octyl- }
\end{array}
$$<smiles>[R2]OC(=O)c1cc2ccccc2cc1O</smiles>

$$
\begin{aligned}
& 26: \mathrm{R}_{4}=\mathrm{Me}- \\
& 27: \mathrm{R}_{4}=\mathrm{Ph}-\mathrm{Me}- \\
& 28: \mathrm{R}_{4}=i-\mathrm{Pr}- \\
& 29: \mathrm{R}_{4}=n-\mathrm{Bu}- \\
& 30: \mathrm{R}_{4}=\mathrm{Cy}- \\
& 31: \mathrm{R}_{4}=n-\text { Octyl- }
\end{aligned}
$$

Scheme 1. Synthesis route of compounds 1-31.

\subsection{Physiological Assays}

At the end of the algicidal experiments on compound 24 and CIA, the M. aeruginosa cells were harvested, and the cell pellets were collected after centrifugation, and subjected to the measurements of the following assays. The content of total soluble protein was 
determined by the Coomassie brilliant blue G-250 staining method [19]. An appropriate amount of algal cell pellets was taken, resuspended by phosphate buffer saline (PBS), and broken by ultrasonication in an ice bath. The supernatant was taken after centrifugation at $4{ }^{\circ} \mathrm{C}$. Coomassie brilliant blue G250 dye solution was added into the supernatant, and the supernatant was shaken and mixed completely. A spectrophotometer was used to detect the absorbance of the prepared solution at $595 \mathrm{~nm}$.

The activity of superoxide dismutase (SOD) was determined by the WST-1 method [20], using the SOD assay kit provided by Nanjing Jiancheng Bioengineering Institute (Nanjing, China) and strictly according to the manufacturer's instructions.

The content of malondialdehyde (MDA) in cells was determined by thiobarbituric acid colorimetry [21]. An appropriate amount of algal cell pellets was taken, resuspended by PBS, and broken by ultrasonication in an ice bath. The supernatant was taken after centrifugation and stored at $-20^{\circ} \mathrm{C}$ for subsequent operation. MDA was measured by the MDA assay kit obtained from Abcam (Cambridge, MA, USA).

\subsection{D-QSAR Model Study}

All 34 compounds including synthesized compounds (1-31) and parent compounds (CIA, CA, and HNA) were utilized as a training set for 3D-QSAR modeling. Compounds $\mathbf{1}$, $3,10,16,20,25$, and 31 were randomly selected as an external test set for validation of the constructed models. The inhibitory ability of the compounds $\left[\mathrm{EC}_{50}(\mu \mathrm{mol} / \mathrm{L})\right]$ was changed to a negative logarithmic scale $\left[\mathrm{pEC}_{50}(\mu \mathrm{mol} / \mathrm{L})\right]$, and then used for subsequent QSAR analyses as a response variable. The operation was performed based on the comparative molecular field analysis (CoMFA) method by Discovery Studio 3.5. The whole modeling process was referenced to the previous publication [22].

\subsection{Statistical Analysis}

All the experiments were conducted in triplicate. Dunnett's multiple comparisons test, following one-way analysis of variance, was used to statistically analyze the data using GraphPad Prism version 7.0 software for Windows (USA). Values were considered significant when $p<0.05$. Principal co-ordinates analysis (PCoA) was performed using vegan package in $\mathrm{R}$ version 4.0 to explore the characteristics of compounds and cyanobacteria based on the data of the algicidal activity.

\section{Results}

\subsection{Algicidal Activity of Synthesized Compounds}

The algicidal activity of the synthesized compounds 1-31 against $M$. aeruginosa, $M$. wesenbergii, $M$. flos-aquae, Ap. flos-aquae, and An. flos-aquae was evaluated with the parent compounds CA, CIA, and HNA as positive controls. The $\mathrm{EC}_{50}$ data of each compound are summarized in Table 1. To help explain the results, we carried out PCoA based on the compounds and cyanobacteria, respectively, and the two-dimensional scatter plots are shown in Figure 1.

Generally, of all synthesized compounds, CIA esters exhibited better algicidal effects than other compound series. Compounds 15-21 from CIA esters, synthesized by cinnamic acid and fatty alcohols, showed strong activities against these cyanobacteria except $A n$. flos-aquae with $\mathrm{EC}_{50}$ values of $0.63-24.51 \mu \mathrm{mol} / \mathrm{L}$. The scatter plot of PCoA also showed these compounds were gathered in the upper left corner (Figure 1A); the second axis seemed to sort the compounds by algicidal activity, and the large loading value presented a higher algicidal activity. The activities of most CIA esters against $M$. wesenbergii, $M$. flos-aquae, and Ap. flos-aquae were even better than that of CIA. Some synthesized CIA esters, e.g., compounds 16-19, 21, and 24, showed a relative selectivity in cyanobacteria inhibition. For instance, compound $\mathbf{2 4}$ showed excellent inhibition activities against $M$. aeruginosa and Ap. flos-aquae with $\mathrm{EC}_{50}$ of $1.38-5.29 \mu \mathrm{mol} / \mathrm{L}$; however, its inhibition activities against other cyanobacteria species were moderate with $\mathrm{EC}_{50}$ of $26.58-(>100) \mu \mathrm{mol} / \mathrm{L}$. Compounds 17-19, and 21 showed excellent inhibition activities against Ap. flos-aquae with 
$\mathrm{EC}_{50}$ of $0.63-6.06 \mu \mathrm{mol} / \mathrm{L}$; however, their inhibition activities against other cyanobacteria species were moderate with $\mathrm{EC}_{50}$ of 11.69-81.57 $\mu \mathrm{mol} / \mathrm{L}$. Compound 16 showed excellent inhibition activities against $M$. wesenbergii and Ap. flos-aquae with $\mathrm{EC}_{50}$ of $5.56-5.59 \mu \mathrm{mol} / \mathrm{L}$; however, its inhibition activities against other cyanobacteria species were moderate with $\mathrm{EC}_{50}$ of $10.72-39.9 \mu \mathrm{mol} / \mathrm{L}$.

The algicidal activities of HNA esters presented a strong specificity. Most HNA esters including compounds $27\left(\mathrm{EC}_{50}=8.48 \mu \mathrm{mol} / \mathrm{L}\right), 29\left(\mathrm{EC}_{50}=9.93 \mu \mathrm{mol} / \mathrm{L}\right), 30\left(\mathrm{EC}_{50}=2.56 \mu \mathrm{mol} / \mathrm{L}\right)$, and $31\left(\mathrm{EC}_{50}=5.94 \mu \mathrm{mol} / \mathrm{L}\right)$ exhibited excellent inhibition activities against Ap. flos-aquae, which are much better than HNA $\left(\mathrm{EC}_{50}=66.58 \mu \mathrm{mol} / \mathrm{L}\right)$. However, their algicidal activities were much lower against other cyanobacteria species. The scatter plot of PCoA showed these HHA esters were assembled on the right side (Figure 1A), implying the large loading value on the first axis might have a selectivity for the algicidal activity.

Table 1. Algicidal activities of the synthesized compounds 1-31 and parent compounds.

\begin{tabular}{|c|c|c|c|c|c|c|}
\hline \multirow{2}{*}{\multicolumn{2}{|c|}{ Compounds }} & \multicolumn{5}{|c|}{$\mathrm{EC}_{50}(\mu \mathrm{mol} / \mathrm{L})$} \\
\hline & & \multirow{2}{*}{$\begin{array}{c}\text { M. } \\
\text { aeruginosa } \\
>100\end{array}$} & \multirow{2}{*}{$\begin{array}{c}\text { M. } \\
\text { wesenbergii } \\
>100\end{array}$} & \multirow{2}{*}{$\begin{array}{c}\text { M. } \\
\text { flos-aquae } \\
>100\end{array}$} & \multirow{2}{*}{$\begin{array}{c}\text { Ap. } \\
\text { flos-aquae } \\
>100\end{array}$} & \multirow{2}{*}{$\begin{array}{c}\begin{array}{c}\text { An. } \\
\text { flos-aquae }\end{array} \\
>100\end{array}$} \\
\hline \multirow{5}{*}{ CA esters } & $\mathbf{1}$ & & & & & \\
\hline & 2 & $>100$ & $>100$ & $>100$ & $>100$ & $>100$ \\
\hline & 3 & 61.52 & 65.00 & 73.40 & 55.01 & $>100$ \\
\hline & 4 & 32.50 & 24.10 & 23.20 & 75.15 & $>100$ \\
\hline & 5 & 27.40 & 64.90 & 31.50 & 24.10 & $>100$ \\
\hline \multirow{7}{*}{ CA amides } & 6 & 27.54 & 10.82 & 7.27 & 54.80 & $>150$ \\
\hline & 7 & 70.38 & 27.24 & 3.59 & 85.30 & 69.59 \\
\hline & 8 & $>100$ & $>100$ & 80.00 & 28.00 & $>150$ \\
\hline & 9 & $>100$ & $>100$ & $>100$ & 50.56 & 75.63 \\
\hline & 10 & 89.30 & $>100$ & 87.00 & 58.80 & 93.88 \\
\hline & 11 & $>100$ & 62.50 & $>100$ & 42.10 & $>150$ \\
\hline & 12 & 115.40 & 109.60 & $>100$ & 19.10 & 121.4 \\
\hline \multirow{12}{*}{ CIA esters } & 13 & 65.54 & $>100$ & $>100$ & 92.78 & 88.81 \\
\hline & 14 & 99.60 & 43.42 & 38.60 & 14.49 & $>100$ \\
\hline & 15 & 20.55 & 7.73 & 13.70 & 22.72 & 36.89 \\
\hline & 16 & 10.72 & 5.56 & 19.61 & 5.59 & 39.9 \\
\hline & 17 & 15.26 & 11.69 & 16.47 & 3.94 & 81.57 \\
\hline & 18 & 13.93 & 13.17 & 12.56 & 0.63 & 61.15 \\
\hline & 19 & 20.81 & 13.81 & 11.78 & 4.59 & 30.27 \\
\hline & 20 & 18.98 & 18.82 & 14.15 & 14.84 & 82.09 \\
\hline & 21 & 24.51 & 13.88 & 11.77 & 6.06 & 57.33 \\
\hline & 22 & 80.72 & $>100$ & 71.31 & 89.85 & $>100$ \\
\hline & 23 & 15.29 & 27.81 & 21.66 & 14.36 & $>100$ \\
\hline & 24 & 1.38 & 38.62 & 26.58 & 5.29 & $>100$ \\
\hline \multirow{7}{*}{$\begin{array}{l}\text { HNA } \\
\text { esters }\end{array}$} & 25 & 33.84 & 105.60 & $>100$ & 62.45 & $>100$ \\
\hline & 26 & 32.34 & 46.26 & $>100$ & 11.39 & $>100$ \\
\hline & 27 & 24.47 & 134.68 & $>100$ & 8.48 & $>100$ \\
\hline & 28 & 61.62 & $>100$ & $>100$ & 81.31 & $>100$ \\
\hline & 29 & 28.35 & 44.44 & $>100$ & 9.93 & 37.99 \\
\hline & 30 & 14.34 & 15.88 & $>100$ & 2.56 & 38.23 \\
\hline & 31 & 35.50 & 55.10 & $>100$ & 5.94 & 224.24 \\
\hline \multirow{3}{*}{ Controls } & $\mathrm{CA}$ & 6.18 & 44.00 & 3.13 & 74.00 & 138.00 \\
\hline & CIA & 3.87 & 85.88 & 169.92 & 26.10 & $>200$ \\
\hline & HNA & 43.84 & 117.18 & $>100$ & 66.58 & 84.64 \\
\hline
\end{tabular}




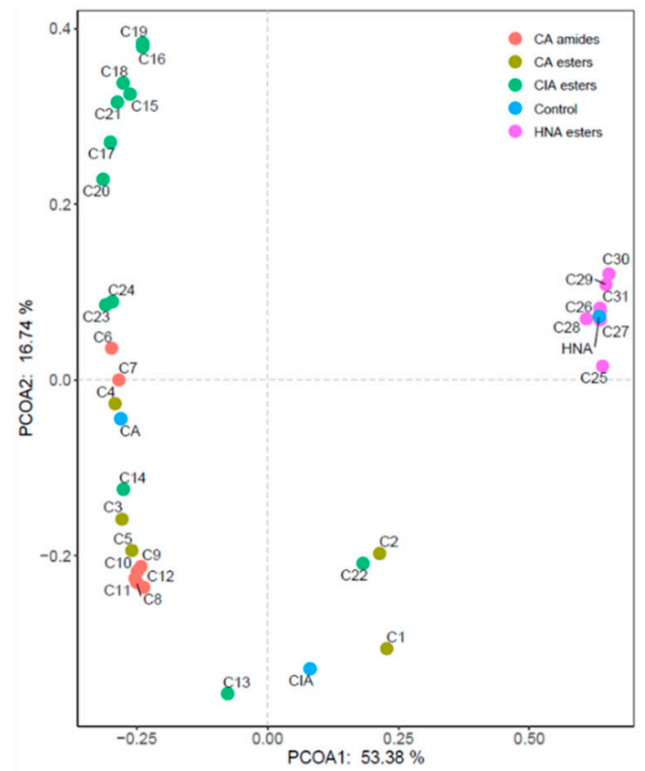

B

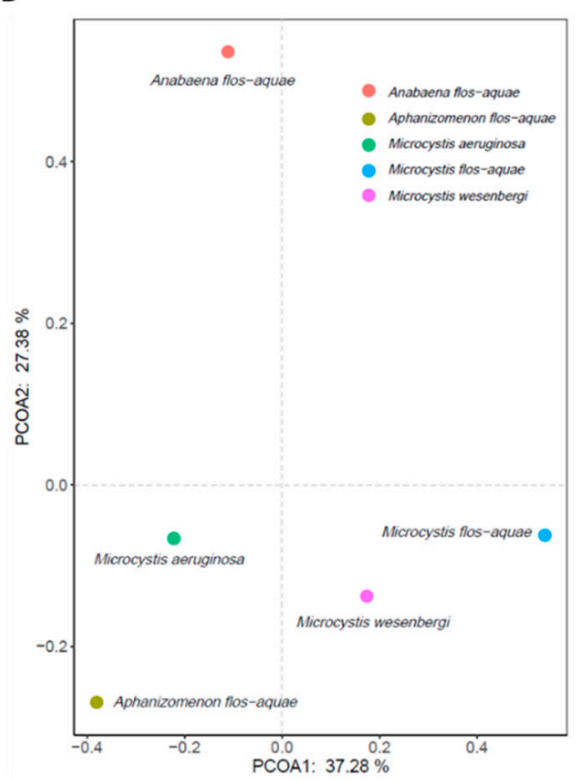

Figure 1. Scatter plots of the first and second principal coordinates of PCoA. (A): PCoA analysis based on compounds. (B): PCoA analysis based on cyanobacteria.

Typically, the CA esters and amides did not achieve good algicidal effects. Only two CA amides, compounds $6\left(\mathrm{EC}_{50}=7.27 \mu \mathrm{mol} / \mathrm{L}\right)$ and $7\left(\mathrm{EC}_{50}=3.59 \mu \mathrm{mol} / \mathrm{L}\right)$, exhibited good inhibition activities against $M$. flos-aquae, and their activities were comparable to CA's.

In terms of cyanobacteria species, An. flos-aquae showed a strong recalcitrance to these synthesized compounds. Only CIA esters and some HNA esters (compounds 29 and 30) exhibited a moderate algicidal activity on An. flos-aquae. The highest algicidal activity against An. flos-aquae was achieved by compound 19 with an $\mathrm{EC}_{50}$ of $30.27 \mu \mathrm{mol} / \mathrm{L}$. In the scatter plot of PCoA, An. flos-aquae was significantly alienated from other cyanobacterial species (Figure 1B), suggesting its resistance to the inhibition effects of the synthesized compounds.

\subsection{Structure-Activity Relationship Analysis}

CIA series were the most active compounds with a broad-spectrum algicidal activity among these synthesized compounds. Compound 18 exhibited the best inhibition activities on four cyanobacteria species, and a moderate activity on An. flos-aquae. Its inhibitory activity on Ap. flos-aquae even reached $0.63 \mu \mathrm{mol} / \mathrm{L}$, which is far stronger than the positive control CIA $\left(\mathrm{EC}_{50}=26.1 \mu \mathrm{mol} / \mathrm{L}\right)$. Compound 18 was synthesized by CIA and naphthol. However, the activity of compound 22 containing a benzene ring was much lower than compound 18, suggesting that the naphthalene ring might provide a higher binding ability to the target than the benzene ring. Moreover, the activity of compound 18 was also slightly stronger than that of other CIA fatty alcohol esters (compounds 15-17, 19-21, 23, and 24), demonstrating the importance of the substituent of the naphthalene ring.

Further, we analyzed the activities of CIA fatty alcohol esters against these five cyanobacteria species and the structure-activity relationship seemed to be contradictive on different species. The compounds with branched chains $(15,19$, and 21$)$ had lower activities against $M$. aeruginosa, while compounds with straight chains $(\mathbf{1 7}, \mathbf{2 0}, \mathbf{2 3}$, and 24) and ring structure (16) had better activities. Among them, compound 24 with the best activity was n-octyl cinnamate, which had the longest chain structure. The inhibition activity test on $M$. wesenbergii showed that the most active compound was cyclohexyl cinnamate (compound 16), and there was no significant difference in activities between compounds with branched and straight chains. The compounds' inhibition against $M$. flos-aquae showed that compounds 15, 19, and 21 with branched chains were slightly more active than those with straight chains (17, 20, 23, and 24) and ring structure (16). After analysis of the compounds' inhibition activities against Ap. flos-aquae, it was shown that 
there was no significant difference between compounds with branched and straight chains. In addition, the algicidal assays on An. flos-aquae found that compounds 15 and 19 with branched chains showed better activities than other compounds.

Compared with CIA esters, CA esters have meta- and para- hydroxyl substituents in the benzene ring; however, the activities of CA esters were greatly reduced. The possible reason is that hydroxyl substituents attenuate the aromaticity and steric structure of the benzene ring, thus affecting the binding ability of the compound to the target. The algicidal activities of HNA series compounds were stronger than the CA series but weaker than the CIA series, which may be related to the fact that the aromaticity of the naphthalene ring is slightly lower than that of the benzene ring.

Although CIA, CA, and other phenolic acids have been reported as allelochemicals to inhibit cyanobacteria growth, this is the first report that their ester and amide derivatives have inhibitory activities on the growth of cyanobacteria. By analyzing the data of this study, it can be found that compounds with some structures have the potential to be developed as algicides. Among these three series of ester derivatives, compounds 5, 16, and 30 with cyclohexyl ester substituents exhibited superior algicidal activities. It is worth mentioning that the inhibitory activities of these three compounds on Ap. flos-aquae are the best, which means they have potential to be developed as selective algaecides against Ap. flos-aquae. The steric hindrance near the ester group may be helpful to improve the activities of these compounds.

Steric hindrance can also enhance the activities of other compounds with large substituents. Octyl cinnamate (24) and octyl 3-hydroxy-2-naphthoate (31) exhibited good inhibitory activities on $M$. aeruginosa and Ap. flos-aquae. The $\mathrm{EC}_{50}$ value of compound 24 on $M$. aeruginosa reached $1.38 \mu \mathrm{mol} / \mathrm{L}$, and it has the potential to be a selective algicide against $M$. aeruginosa.

\subsection{D-QSAR Analysis}

In order to further explore the correlation between the structure and activity of the compounds, and to provide guidance for the development of more potent algicides, a series of 3D-QSAR models were established based on the algicidal activities of the synthesized compounds in this study.

Before establishing the 3D-QSAR models, benzyl was chosen as a substructure to align the structure of the compounds. In the modelling, seven compounds were selected as the test set, while the rest of the compounds were used as the training set. The operation process mainly referred to the previous literature [22].

As shown in Figure 2A, the cross-validation correlation coefficient $\left(q^{2}\right)$ values of the five constructed models were between 0.9 and 1 , which proves that these models are credible [23]. The predicted and experimental $\mathrm{pEC}_{50}$ values of the 31 compounds are listed in the Supplementary Materials Table S1. Plots of the experimental $\mathrm{pEC}_{50}$ versus the predicted values are provided in Figure 2B-F.

Moreover, the molecules aligned with the iso-surfaces of the 3D-QSAR model coefficients on electrostatic potential grids (Figure 3A-E) and van der Waals grids (Figure 3F-J) are shown. As described previously, the electrostatic map indicated red contours around regions where high electron density (negative charge) was expected to increase the activity, and blue contours represented areas where low electron density (partial positive charge) was expected to increase the activity [24]. The steric map derived from van der Waals analysis indicated areas where steric bulk was predicted to increase (green) or decrease (yellow) the activity [24]. 
A

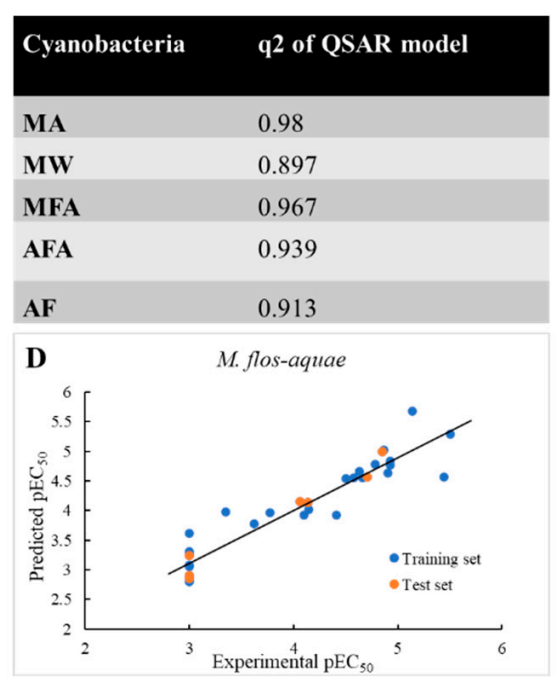

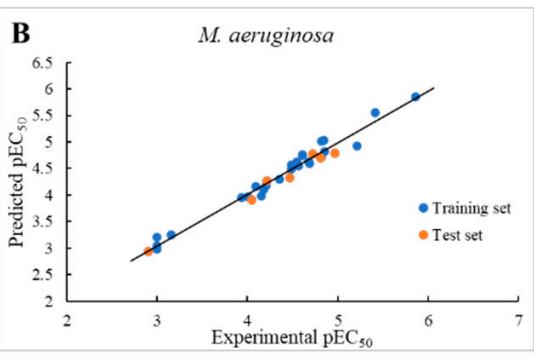

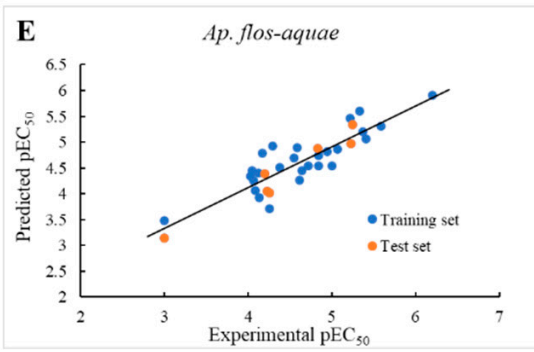

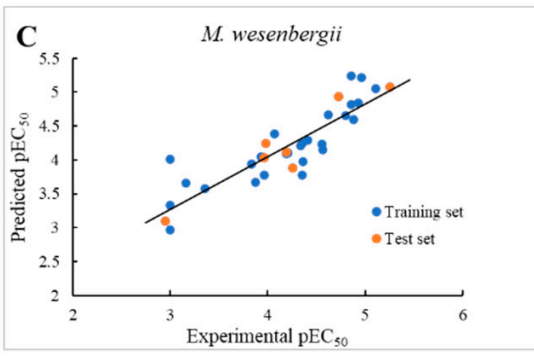

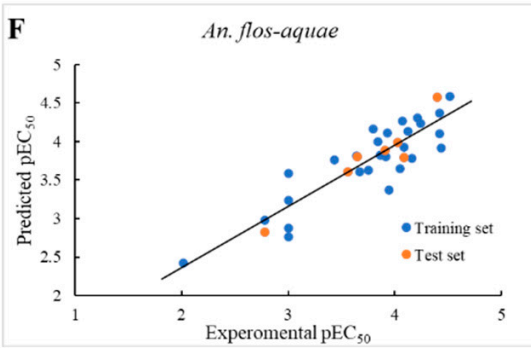

Figure 2. 3D-QSAR analysis results of compounds' inhibitory effects on cyanobacteria. (A): $q^{2}$ values of all five 3D-QSAR models. (B-F): Plots of the predicted and experimental $\mathrm{pEC}_{50}$ values of the training and test sets.

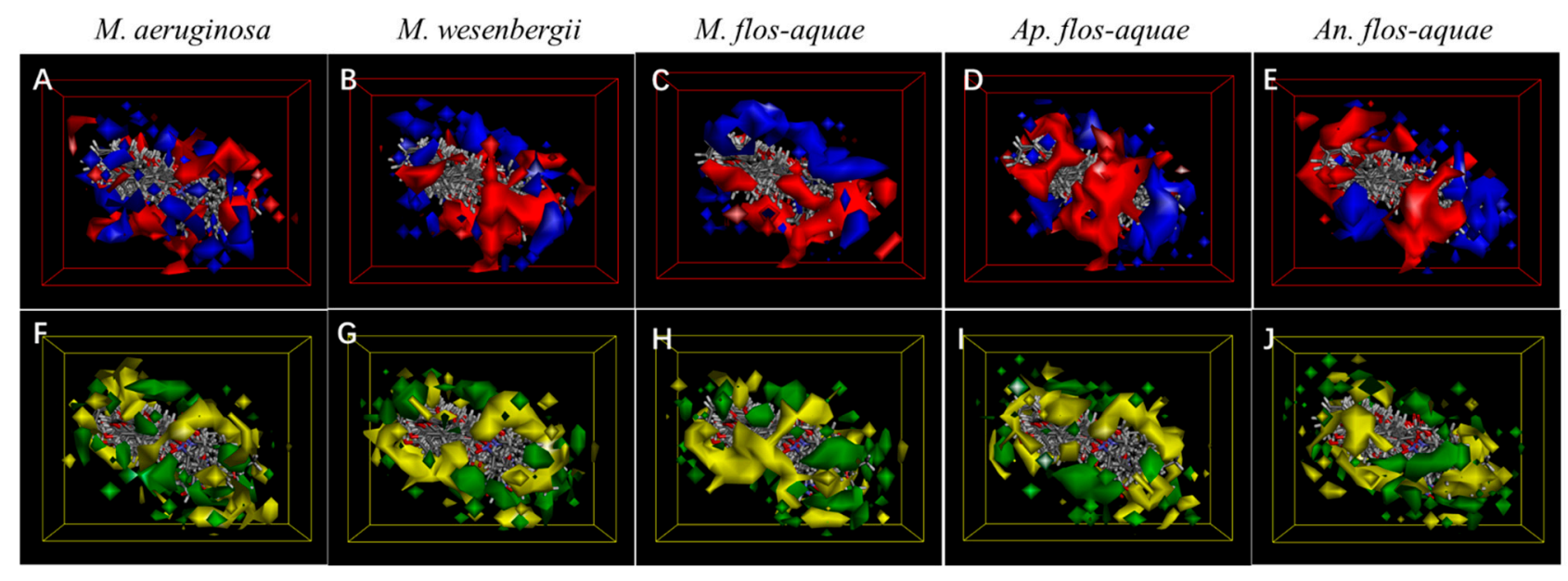

Figure 3. (A-E) 3D-QSAR model coefficients on electrostatic potential grids. Blue represents positive coefficients, and red represents negative coefficients. (F-J) 3D-QSAR model coefficients on van der Waals grids. Green represents positive coefficients, and yellow represents negative coefficients.

For the models of $M$. aeruginosa, $M$. wesenbergii, and $M$. flos-aquae, the benzene ring from the acid group was mainly occupied by blue (Figure 3A-E), indicating that the low electron density would increase the activity of compounds, which is consistent with the previous activity evaluation result, i.e., when there were substituent groups with high electron density on the benzene ring, such as the hydroxyl substituent, or when the benzene ring was replaced by the naphthalene ring, the activity was affected. However, for the models of Ap. flos-aquae and An. flos-aquae, the benzene ring of the compounds was mainly occupied by red, and the high electron density would be beneficial for enhancing the activity. The algicidal activity evaluation results also showed that the naphthalene ring in the HNA ester compounds could enhance the activity against Ap. flos-aquae or An. flos-aquae.

As shown in Figure 3F-J, the compounds with small substituent groups in the benzene ring from the acid group exhibited better activities against all five cyanobacteria species, which confirmed that the hydroxyl substituents in the benzene ring influenced the activity of the compounds. Moreover, the naphthyl ring also influenced the activity. For the 
substituents, the corresponding models of different cyanobacteria species were different, but it was clear that for the compounds with aromatic substituents, yellow occupied the main position, indicating that the large substituents weaken the activity. Meanwhile for the fatty alcohol ester substituents, green occupied the main position, suggesting that big substituents could enhance the activity. In the previous structure-activity relationship analysis (Section 3.2), we mentioned that the steric hindrance of fatty alcohol chains could enhance the activity, while the benzene substituents, such as nitrobenzene, could seriously affect the activity. This is consistent with the results of QSAR analysis.

\subsection{Physiological Assays}

In order to further explore the inhibition mechanism of the synthesized compounds on cyanobacteria, we investigated the possible mechanisms involved in the inhibition process, including superoxide dismutase (SOD) activity, soluble protein content, and membrane lipid peroxidation. Compound $\mathbf{2 4}$ with the best algicidal activity on M. aeruginosa was chosen as an example and CIA was used as the control.

Under conditions of oxidative stress, SOD acts as an endogenous cellular defense barrier that degrades superoxide $\left(\mathrm{O}_{2}{ }^{\bullet-}\right)$ into oxygen and hydrogen peroxide, with the latter being further decomposed by glutathione peroxidase or catalase [25]. After treating M. aeruginosa with compound $\mathbf{2 4}$ and CIA for $72 \mathrm{~h}$, the cellular SOD activity was measured, and the results are shown in Figure $4 \mathrm{~A}$. It can be seen that after exposure to compound 24 of $5 \mu \mathrm{mol} / \mathrm{L}$, the SOD activity in M. aeruginosa decreased by $36.68 \%$, whereas the activity of SOD did not change significantly after exposure of CIA of $5 \mu \mathrm{mol} / \mathrm{L}$. This result indicated that compound $\mathbf{2 4}$ could influence the antioxidant defense system in $M$. aeruginosa, which might be related to the inhibition of the growth of $M$. aeruginosa. CIA had little effect on SOD activity at this concentration, suggesting that suppressing the SOD activity might not be the main mechanism of CIA inhibition on M. aeruginosa.

A

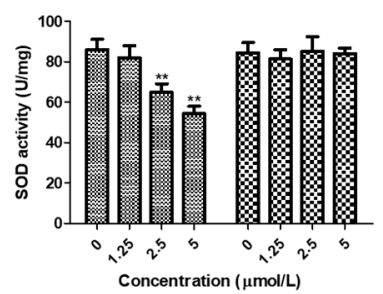

B

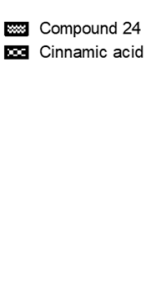

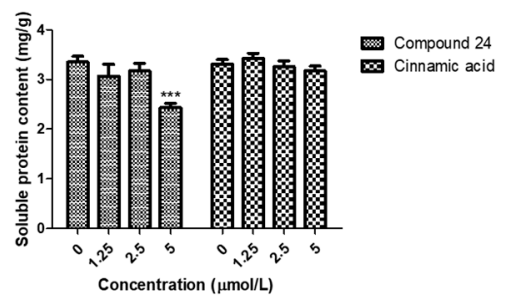

C

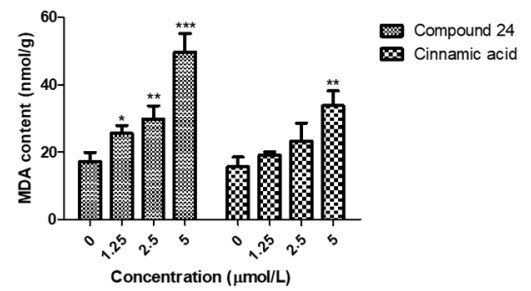

Figure 4. Superoxide dismutase (SOD) activity (A), and contents of soluble protein (B) and malondialdehyde (MDA) (C) in M. aeruginosa after 72-h exposure to compound 24 and CIA $(0,1.25,2.5$, and $5 \mu \mathrm{mol} / \mathrm{L})$. Data are presented as mean values \pm standard deviation $(\mathrm{n}=3) .{ }^{*} p<0.05,{ }^{* *} p<0.01,{ }^{* * *} p<0.001$ vs. $0 \mu \mathrm{mol} / \mathrm{L}$.

The changes of soluble proteins in M. aeruginosa in the exposure experiment are shown in Figure 4B. The soluble protein content in M. aeruginosa did not change significantly after treatment with CIA for $72 \mathrm{~h}$. After the 72-h treatment of compound 24 on M. aeruginosa, only when the concentration increased to $5 \mu \mathrm{mol} / \mathrm{L}$ did the soluble protein content decrease by $27.46 \%$. This result indicated that the main mechanism of compound 24 and CIA inhibiting the growth of $M$. aeruginosa was not through hindering of the synthesis of soluble proteins.

Malondialdehyde (MDA) is the product of membrane lipid peroxidation. The accumulated MDA can damage the membrane structure and function, increase membrane permeability, make cell metabolism imbalanced, and destroy the progress of various reactions in cells, even leading to cell death in severe cases [26]. In this experiment, it was found that when the concentrations of CIA and compound 24 were higher than $1.25 \mu \mathrm{mol} / \mathrm{L}$, the MDA content of $M$. aeruginosa gradually increased. When the concentration of compound 24 was $1.25 \mu \mathrm{mol} / \mathrm{L}$, the content of MDA increased significantly $(p<0.05)$. The change trends of MDA in the CIA-treated group and compound 24-treated group were basically the same. This result indicated that CIA and compound 24 could significantly 
promote cell membrane lipid peroxidation, cause the accumulation of MDA, and finally inhibit the growth of $M$. aeruginosa.

\section{Discussion}

Due to the frequent outbreaks of cyanobacteria bloom, research on novel algicides has attracted more and more attention. At present, the reported algicides mainly focus on allelochemicals. In a study on $M$. aeruginosa inhibitors, researchers found that some plant extracts had good inhibitory effects, such as rice straw extract, L. camara leave extracts, etc. [27-29]. Further studies found that some allelochemicals with a single component also had inhibitory effects, such as gramine, cinnamic acid, artemisinin, etc. [9,30]. However, few articles on structural modification of these allelochemicals have been published. In this study, phenolic acid derivatives were innovatively synthesized as potential algicides, and lead compounds with excellent activity were found. Taking the inhibitors on $M$. aeruginosa for example, the $\mathrm{EC}_{50}$ of the best active compound 24 reached $1.38 \mu \mathrm{M}(0.36 \mathrm{mg} / \mathrm{L})$, while the $\mathrm{EC}_{50}$ values of previously reported allelochemicals have been basically at the $\mathrm{mg} / \mathrm{L}$ level $[9,31,32]$. This result indicates that the algicides reported in this study are more efficient in inhibiting cyanobacteria with a lower concentration than most previously reported allelochemicals.

As part of the aquatic ecosystem, cyanobacteria are closely related to other organisms in the water, such as aquatic plants, fish, and zooplankton. Therefore, it is very important for the use of algicides that they just kill cyanobacteria without harming other species. Meanwhile, there are many kinds of cyanobacteria species in the water, and not all cyanobacteria species will cause water bloom. In the famous reported cyanobacteria bloom events in history, the dominant cyanobacteria species are also different. For example, in the Darling River cyanobacteria bloom event in 1991, the dominant cyanobacteria species was Anabaena [33]. In the Taihu Lake cyanobacteria bloom event in 2007, the dominant cyanobacteria species were $M$. aeruginosa and $M$. wesenbergii [16,34]. In the Dianchi Lake cyanobacteria bloom in 2007, the dominant cyanobacteria species were M. aeruginosa and Ap. flos-aquae [35]. Therefore, it is very important to employ selective algicides to control specific cyanobacteria bloom.

In this study, we found that CIA esters could inhibit the growth of water bloomforming cyanobacteria, and some compounds had strong selectivity. For instance, the $\mathrm{EC}_{50}$ of compound 18 to $A p$. flos-aquae was as low as $0.63 \mu \mathrm{M}$, while its activities against other cyanobacteria species were greater than $10 \mu \mathrm{M}$. The $\mathrm{EC}_{50}$ of compound 24 on $M$. aeruginosa was as low as $1.38 \mu \mathrm{M}$, while its activities on M. wesenbergii $\left(\mathrm{EC}_{50}=38.62 \mu \mathrm{M}\right)$ and Microcystis flos-aquae $\left(\mathrm{EC}_{50}=26.58 \mu \mathrm{M}\right)$ were much lower. These results indicated that these compounds could still inhibit cyanobacteria growth at low concentrations. Another important finding of this study is that the selective inhibition of naphthoic acid ester derivatives on Ap. flos-aquae was generally stronger than that on other cyanobacteria species, making us strongly interested in this compound skeleton. The mechanism underlying the inhibition effect is worthy of further investigation. From the environmentally friendly aspect, it was necessary to find out selective algicides without harming other species. In this study, we just validated the selectivity of algicides on different cyanobacteria. The effects of these algicides on other species, like microalgae and zooplankton, need to be clarified in the future.

With the development of drug discovery, more and more new types of algicides have emerged, such as metal organic chelates, nanomaterials, etc. [36,37]. Compared with these new algicides, the allelochemical relatives reported in this study may be more environmentally friendly with a lower cost and higher application value.

\section{Conclusions}

In general, the synthesized compounds especially CIA esters, exhibited excellent inhibitory activities against multiple cyanobacteria species except An. flos-aquae. Although some of the other series of compounds except CIA esters were not as active as the controls, 
all of the synthesized compounds showed obvious advantages, including easy synthesis and low cost. Structure-activity analysis and 3D-QSAR modelling demonstrated that steric hindrance could enhance the activity of CIA esters, and provided theoretical guidance for prediction of the activities and further structure optimization of the compounds. The physiological assays preliminarily revealed that the possible action mechanism of CIA esters might involve cell membrane lipid peroxidation. Therefore, CIA esters as a new type of algal inhibitors have great potential as lead compounds for the development of environmentally friendly algicides. This result has provided a direction for further design and optimization of the chemical structure of potential algicides.

Supplementary Materials: The following are available online at https: / / www.mdpi.com/article/10.3 390/biology10111145/s1, Supplementary Materials S1: The characterization data of compounds 1-31, Table S1: Predicted and experimental $\mathrm{pEC}_{50}$ values of 3D-QSAR models.

Author Contributions: Conceptualization, J.F.; methodology, Y.L.; software, Y.Y.; validation, Y.Y.; formal analysis, Y.L.; investigation, Y.L.; resources, W.H.; data curation, Y.L.; writing-original draft preparation, Y.L.; writing-review and editing, J.F.; visualization, W.H.; supervision, J.F.; project administration, J.F.; funding acquisition, J.F. All authors have read and agreed to the published version of the manuscript.

Funding: This research was funded by National Natural Science Foundation of China, grant number 91851110 and Hubei Provincial Natural Science Foundation of China, grant number 2020CFA106.

Institutional Review Board Statement: Not applicable.

Informed Consent Statement: Not applicable.

Data Availability Statement: Data are contained within the article, and materials can be requested from the authors upon reasonable request.

Conflicts of Interest: The authors declare no conflict of interest.

\section{References}

1. Cai, W.-J.; Hu, X.; Huang, W.-J.; Murrell, M.; Lehrter, J.C.; Lohrenz, S.; Chou, W.-C.; Zhai, W.-D.; Hollibaugh, J.T.; Wang, Y.; et al. Acidification of subsurface coastal waters enhanced by eutrophication. Nat. Geosci. 2011, 4, 766-770. [CrossRef]

2. Zhu, Y.; Ling, J.; Li, L.; Guan, X. The effectiveness of bisulfite-activated permanganate technology to enhance the coagulation efficiency of Microcystis aeruginosa. Chin. Chem. Lett. 2020, 31, 1545-1549. [CrossRef]

3. $\mathrm{Fu}, \mathrm{J}$. Issue of Cyanobacteria Blooms in Taihu Lake, China. J. Environ. Sci. Manag. 2016, 19, 99-109.

4. Hernandez, B.Y.; Zhu, X.; Sotto, P.; Paulino, Y. Oral exposure to environmental cyanobacteria toxins: Implications for cancer risk. Environ. Int. 2021, 148, 106381. [CrossRef] [PubMed]

5. Xiong, J.; Xie, R.; Zhang, H.; Gao, J.; Wang, J.; Liang, Q. Nitrite-responsive hydrogel for long-term and smart control of cyanobacteria bloom. J. Hazard. Mater. 2021, 411, 125150. [CrossRef]

6. Leao, P.N.; Pereira, A.R.; Liu, W.-T.; Ng, J.; Pevzner, P.A.; Dorrestein, P.C.; Konig, G.M.; Vasconcelos, V.M.; Gerwick, W.H. Synergistic allelochemicals from a freshwater cyanobacterium. Proc. Natl. Acad. Sci. USA 2010, 107, 11183-11188. [CrossRef] [PubMed]

7. Zhang, X.-W.; Fu, J.; Song, S.; Zhang, P.; Yang, X.-H.; Zhang, L.-R.; Luo, Y.; Liu, C.-H.; Zhu, H.-L. Interspecific Competition between Microcystis aeruginosa and Anabaena flos-aquae from Taihu Lake, China. Z. Naturforsch. C 2014, 69, 53-60. [CrossRef] [PubMed]

8. Nakai, S.; Inoue, Y.; Hosomi, M. Algal growth inhibition effects and inducement modes by plant-producing phenols. Water Res. 2001, 35, 1855-1859. [CrossRef]

9. Ni, L.; Acharya, K.; Hao, X.; Li, S. Isolation and identification of an anti-algal compound from Artemisia annua and mechanisms of inhibitory effect on algae. Chemosphere 2012, 88, 1051-1057. [CrossRef]

10. Gao, Y.N.; Liu, B.Y.; Ge, F.J.; He, Y.; Lu, Z.Y.; Zhou, Q.H.; Zhang, Y.Y.; Wu, Z.B.; Gao, Y.N.; Liu, B.Y. Joint effects of allelochemical nonanoic acid, N-phenyl-1-naphtylamine and caffeic acid on the growth of Microcystis aeruginosa. Allelopath. J. 2015, 35, $249-257$.

11. He, M.; Zhang, T.; Wu, A.; Nie, L. Inhibition of Cinnamic acid on Microcystis aeruginosa K. and Scenedesmus arcuatus L. Chin. J. Appl. Environ. Biol. 2008, 14, 774-778.

12. Gao, Y.N.; Liu, B.Y.; Xu, D.; Zhou, Q.H.; Hu, C.Y.; Ge, F.J.; Zhang, L.P.; Wu, Z.B. Phenolic Compounds Exuded from Two Submerged Freshwater Macrophytes and Their Allelopathic Effects on Microcystis aeruginosa. Pol. J. Environ. Stud. 2011, 20, 1153-1159. 
13. Zhu, B.; Jun, H.; Ting, S.; Wei, W.; Junyi, Z. Study on the species and succession of cyanobacteria bloom in Taihu Lake. In Proceedings of the 2014 Annual Conference of the Chinese Society for Environmental Science (Chapter 5), Chengdu, China, 22-23 October 2014; pp. 4435-4440.

14. Tan, X.; Kong, F.; Zeng, Q.; Cao, H.; Qian, S.; Zhang, M. Seasonal variation of Microcystis in Lake Taihu and its relationships with environmental factors. J. Environ. Sci. 2009, 21, 892-899. [CrossRef]

15. Yamamoto, Y.; Nakahara, H. The formation and degradation of cyanobacterium Aphanizomenon flos-aquae blooms: The importance of $\mathrm{pH}$, water temperature, and day length. Limnology 2005, 6, 1-6. [CrossRef]

16. Xu, Y.; Wu, Z.; Yu, B.; Peng, X.; Yu, G.; Wei, Z.; Wang, G.; Li, R. Non-microcystin producing Microcystis wesenbergii (Komárek) Komárek (Cyanobacteria) representing a main waterbloom-forming species in Chinese waters. Environ. Pollut. 2008, 156, 162-167. [CrossRef]

17. Wan, J.; Guo, P.; Zhang, S. Response of the cyanobacterium Microcystis flos-aquae to levofloxacin. Environ. Sci. Pollut. Res. 2014, 21, 3858-3865. [CrossRef]

18. Peng, Y.; Zhang, Z.; Wang, M.; Shi, X.; Zhou, Y.; Zhou, Y.; Kong, Y. Inactivation of harmful Anabaena flos-aquae by ultrasound irradiation: Cell disruption mechanism and enhanced coagulation. Ultrason. Sonochemistry 2020, 69, 105254. [CrossRef]

19. Pierce, J.; Suelter, C. An evaluation of the Coomassie brilliant blue G-250 dye-binding method for quantitative protein determination. Anal. Biochem. 1977, 81, 478-480. [CrossRef]

20. Yong, Z.; Tang, H.R.; Luo, Y. Variation in Antioxidant Enzyme Activities of Two Strawberry Cultivars with Short-term Low Temperature Stress. World J. Agric. Sci. 2008, 4, 458-462.

21. Heath, R. Photoperoxidation in isolated chloroplasts: I. Kinetics and stoichiometry of fatty acid peroxidation. Arch. Biochem. Biophys 1968, 125, 189-198. [CrossRef]

22. Luo, Y.; Zhou, Y.; Fu, J.; Zhu, H.-L. 4,5-Dihydropyrazole derivatives containing oxygen-bearing heterocycles as potential telomerase inhibitors with anticancer activity. RSC Adv. 2014, 4, 23904-23913. [CrossRef]

23. Liu, S.; Luo, Y.; Fu, J.; Zhou, J.; Kyzas, G. Molecular docking and 3D-QSAR studies on the glucocorticoid receptor antagonistic activity of hydroxylated polychlorinated biphenyls. SAR QSAR Environ. Res. 2016, 27, 87-99. [CrossRef]

24. Luo, Y.; Zhou, Y.; Song, Y.; Chen, G.; Wang, Y.-X.; Tian, Y.; Fan, W.-W.; Yang, Y.-S.; Cheng, T.; Zhu, H.-L. Optimization of substituted cinnamic acyl sulfonamide derivatives as tubulin polymerization inhibitors with anticancer activity. Bioorganic Med. Chem. Lett. 2018, 28, 3634-3638. [CrossRef]

25. Yasui, K.; Baba, A. Therapeutic potential of superoxide dismutase (SOD) for resolution of inflammation. Inflamm. Res. 2006, 55, 359-363. [CrossRef] [PubMed]

26. Michael, P.I.; Krishnaswamy, M. The effect of zinc stress combined with high irradiance stress on membrane damage and antioxidative response in bean seedlings. Environ. Exp. Bot. 2011, 74, 171-177. [CrossRef]

27. Kong, C.H.; Wang, P.; Zhang, C.X.; Zhang, M.X.; Hu, F. Herbicidal potential of allelochemicals from Lantana camara against Eichhornia crassipes and the alga Microcystis aeruginosa. Weed Res. 2006, 46, 290-295. [CrossRef]

28. Park, M.-H.; Han, M.-S.; Ahn, C.-Y.; Kim, H.-S.; Yoon, B.-D.; Oh, H.-M. Growth inhibition of bloom-forming cyanobacterium Microcystis aeruginosa by rice straw extract. Lett. Appl. Microbiol. 2006, 43, 307-312. [CrossRef] [PubMed]

29. Zhao, W.; Zheng, Z.; Zhang, J.; Roger, S.-F.; Luo, X. Allelopathically inhibitory effects of eucalyptus extracts on the growth of Microcystis aeruginosa. Chemosphere 2019, 225, 424-433. [CrossRef]

30. Hong, Y.; Hu, H.-Y.; Xie, X.; Sakoda, A.; Sagehashi, M.; Li, F.-M. Gramine-induced growth inhibition, oxidative damage and antioxidant responses in freshwater cyanobacterium Microcystis aeruginosa. Aquat. Toxicol. 2009, 91, 262-269. [CrossRef]

31. Hou, X.; Huang, J.; Tang, J.; Wang, N.; Zhang, L.; Gu, L.; Sun, Y.; Yang, Z.; Huang, Y. Allelopathic inhibition of juglone (5-hydroxy1,4-naphthoquinone) on the growth and physiological performance in Microcystis aeruginosa. J. Environ. Manag. 2019, 232, 382-386. [CrossRef] [PubMed]

32. Yi, Y.-L.; Yu, X.-B.; Zhang, C.; Wang, G.-X. Growth inhibition and microcystin degradation effects of Acinetobacter guillouiae A2 on Microcystis aeruginosa. Res. Microbiol. 2015, 166, 93-101. [CrossRef] [PubMed]

33. Bowling, L.; Baker, P. Major cyanobacterial bloom in the Barwon-Darling River, Australia, in 1991, and underlying limnological conditions. Mar. Freshw. Res. 1996, 47, 643-657. [CrossRef]

34. Li, M.; Xiao, M. Environmental factors related to the dominance of Microcystis wesenbergii and Microcystis aeruginosa in a eutrophic lake. Environ. Earth Sci. 2016, 75, 1-8. [CrossRef]

35. Xing, W.; Huang, W.-M.; Liu, Y.-D.; Li, D.; Shen, Y.-W.; Li, G.-B. Environmental mechanism of change in cyanobacterial species composition in the northeastern part of Lake Dianchi (China). Fresen. Env. Bull. 2007, 16, 82-90.

36. Fan, G.; Zhou, J.; Zheng, X.; Chen, W. Growth Inhibition of Microcystis aeruginosa by Copper-based MOFs: Performance and Physiological Effect on Algal Cells. Appl. Organomet. Chem. 2018, 32, e4600. [CrossRef]

37. Sankar, R.; Prasath, B.B.; Nandakumar, R.; Santhanam, P.; Shivashangari, K.S.; Ravikumar, V. Growth inhibition of bloom forming cyanobacterium Microcystis aeruginosa by green route fabricated copper oxide nanoparticles. Environ. Sci. Pollut. Res. 2014, 21, 14232-14240. [CrossRef] 